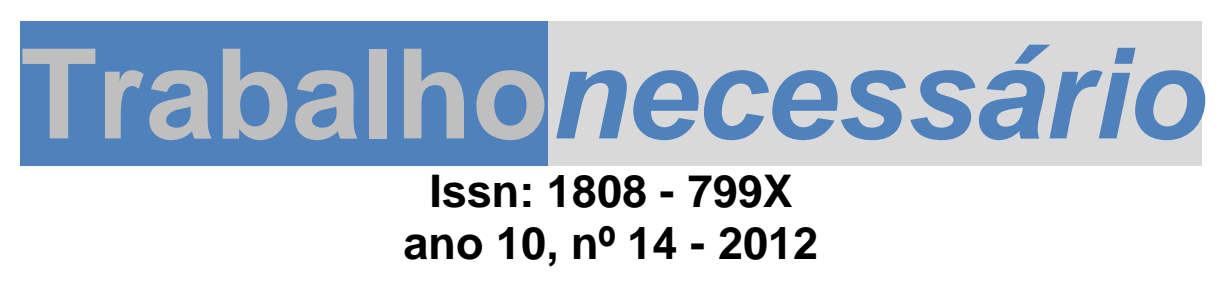

DOCUMENTOS E MEMÓRIA

\title{
SENAI: 70 ANOS
}

Francisco José da Silveira Lobo Neto

\section{Introdução}

Este ano, em que se celebra o tricentenário de nascimento de J.-J. Rousseau, a educação brasileira comemora os 80 anos do "Manifesto dos Pioneiros" e os 70 anos do SENAI. Trazemos à memória dos nossos leitores, os documentos que marcam a origem do Serviço Nacional de Aprendizagem dos Industriários (SENAI), logo depois denominado Serviço Nacional de Aprendizagem Industrial. Talvez tenhamos aí, um sinal semântico de uma primeira retificação de objetivos: passa-se a sublinhar mais a atividade produtiva do que o trabalhador produtor, mais o processo do que o ator.

Por várias razões escolhe-se o SENAI para esta coluna. A primeira porque, mais diretamente, nos traz reflexões sobre o "modo" SENAI de relacionar trabalho e educação. A segunda porque, um fato concreto na regulamentação da educação profissional brasileira relacionado aos "serviços nacionais de aprendizagem" (SENAI, SENAC, SENAR e SENAT) - através do Art. 20 da Lei 12.513/2011 que instituiu o Programa Nacional de Acesso ao Ensino Técnico e Emprego (Pronatec) - integra-os ao Sistema Federal de Ensino. E, mais: concede - Ihes a "autonomia para a criação e oferta de cursos e programas de educação profissional e tecnológica, mediante autorização do órgão colegiado superior do respectivo departamento regional da entidade, resguardada a competência de supervisão e avaliação da União 
prevista no inciso IX do art. $9^{\circ}$ da Lei $n^{\circ}$ 9.394, de 20 de dezembro de 1996". Para o septuagenário SENAI, a antecipação de um "presente" de aniversário.

Afinal de contas, aplica-se analogicamente aos "serviços de aprendizagem" e, portanto, ao SENAI, o disposto sobre a autonomia das Universidades (estendida aos Centros Universitários) no Art. 53 da Lei de Diretrizes e Bases da Educação Nacional. E mais, a ressalva é a mais geral possível, já que a Lei $n^{\circ} 12.513 / 2011$, ao citar o Art. $9^{\circ}$, que trata das incumbências da União na educação em sua alínea IX, cita exclusivamente a "supervisão" e "avaliação", isentando os cursos de obter "autorização", "reconhecimento" e "credenciamento".

Note-se ainda que, ao integrá-los ao Sistema Federal de Ensino, isenta os serviços nacionais de aprendizagem de qualquer influência dos sistemas estaduais e municipais de educação.

E repercute, também, em alteração do Regimento do SENAI, realizada através da Resolução n. 510/2011 ${ }^{1}$ de seu Conselho Nacional, criando o Regulamento da Integração ao Sistema Federal de Ensino. O Regimento previa o seguinte:

"Art. 19. Compete ao Conselho Nacional:

a) estabelecer as diretrizes gerais que devem ser seguidas pela administração nacional e pelas administrações regionais na educação profissional e tecnológica, incluída a aprendizagem industrial, bem como regulamentar a questão da gratuidade tratada nos $\S \S 20$ e 30 do art. $10 ;{ }^{2}(\ldots)$

Art. 40. Compete a cada Departamento Regional:

a) submeter ao Conselho Regional o plano para a realização da aprendizagem na região;

b) estabelecer, mediante aprovação do Conselho Regional, a localização e os planos de instalação de escolas, cursos de aprendizagem e cursos extraordinários para operários maiores de 18 anos..."

Pela Resolução 510/2011:,

a) é explicitada a desvinculação dos sistemas estaduais de ensino, mas aberta a possibilidade de "formas de colaboração e parceria" com os sistemas de ensino (itens 6 a 8);

\footnotetext{
${ }^{1}$ Disponível em http://www.senai.br/upload/publicacoes/arq634642285481459102.pdf acesso em junho de 2012

${ }^{2}$ Vide Nota ${ }^{\circ} 8$.
} 
b) a autonomia dos Conselhos Regionais abrange os cursos técnicos, os cursos de graduação tecnológica e os cursos de pós-graduação, não se estendendo aos cursos de bacharelado e licenciatura (itens 16 a 18);

c) são estabelecidos os padrões mínimos para concretizar as propostas aos Conselhos Regionais para criação de unidades de ensino e de cursos de educação profissional nos diversos níveis (itens 19 a 22);

d) será organizada e implantada uma "estratégia de apoio, supervisão e avaliação interna da educação profissional" pelo Departamento Nacional, em colaboração com os Departamentos Regionais, "independente dos sistemas públicos de supervisão e avaliação da educação profissional e tecnológica" (item 32).

Nos seus setenta anos, o primeiro dentre os Serviços Nacionais de Aprendizagem se apresenta com uma renovada organização, alcançando o mais elevado nível de instituição de ensino. Sem denominar-se Universidade ou Centro Universitário, oferece cursos desde a aprendizagem até a graduação e pós-graduação, criando-os e implementando-os com a autonomia que lhe é conferida por Lei.

E o faz considerando seu compromisso de "oferecer educação profissional e tecnológica de excelência para a indústria e para o país". Mais importante é que este compromisso cumpra ao pé da letra o Documento Primeiro que gerou um Serviço Nacional de Aprendizagem para os "trabalhadores industriários", cujos interesses como cidadãos e trabalhadores devem pautar os projetos de sua educação profissional e tecnológica.

\section{Documentos}

\section{A) DECRETO-LEI № 4.048 - DE 22 DE JANEIRO DE 1942}

\section{Cria o Serviço Nacional de Aprendizagem dos Industriários (SENAI)}

Art. 1 Fica criado o Serviço Nacional de Aprendizagem dos Industriários.

Art. 2o Compete ao Serviço Nacional de Aprendizagem dos Industriários organizar e administrar, em todo o país, escolas de aprendizagem para industriários.

Parágrafo único. Deverão as escolas de aprendizagem, que se organizarem, ministrar ensino de continuação e de aperfeiçoamento e especialização, para trabalhadores industriários não sujeitos à aprendizagem

Art. 3o O Serviço Nacional de Aprendizagem dos Industriários será organizado e dirigido pela Confederação Nacional da Indústria. 
Art. 4 Serão os estabelecimentos industriais das modalidades de indústrias enquadradas na Confederação Nacional da Indústria obrigados ao pagamento de uma contribuição mensal para montagem e custeio das escolas de aprendizagem.

$\S 1^{\circ}$ A contribuição referida nêste artigo será de dois mil réis, por operário e por mês.

$\S 2^{\circ}$ A arrecadação da contribuição de que trata êste artigo será feita pelo Instituto de Aposentadoria e Pensões dos Industriários, sendo o produto posto à disposição do Serviço Nacional de Aprendizagem dos Industriários.

$\S 3^{\circ}$ O produto da arrecadação feita em cada região do país, deduzida a quota necessária às despesas de caráter geral será na mesma região aplicado.

Art. 5o Estarão isentos da contribuição referida no artigo anterior os estabelecimentos que, por sua própria conta, mantiverem, aprendizagem, considerada, pelo Serviço Nacional de Aprendizagem dos Industriários, sob o ponto de vista da montagem, da contribuição do corpo docente e do regime escolar, adequada aos seus fins.

Art. 6 A contribuição dos estabelecimentos que tiverem mais de quinhentos operários será acrescida de vinte por cento.

Parágrafo único. O Serviço Nacional de Aprendizagem dos Industriários aplicará o produto da contribuição adicional referida nêste artigo, em benefício do ensino nêsses mesmos estabelecimentos, quer criando bolsas de estudo a serem concedidas a operários, diplomados ou habilitados, e de excepcional valor, para aperfeiçoamento ou especialização profissional, quer promovendo a montagem de laboratórios que possam melhorar as suas condições técnicas e pedagógicas.

Art. $7^{\circ}$ Os serviços de caráter educativo, organizados e dirigidos pelo Serviço Nacional de Aprendizagem dos Industriários, serão isentos de impostos federais.

Parágrafo único. Serão decretadas isenções estaduais e municipais, em benefício dos serviços de que trata o presente artigo.

Art. 8 A organização do Serviço Nacional de Aprendizagem dos Industriários constará de seu regimento, que será, mediante projeto apresentado ao Ministro da Educação pela Confederação Nacional da Indústria, aprovado por decreto do Presidente da República.

Art. 9 A contribuição, de que trata o art. 4ํ deste decreto-lei, começará a ser cobrada, no corrente ano, a partir de 1 de abril.

Art. 10. Êste decreto-lei entrará em vigor na data de sua publicação. 
Art. 11. Ficam revogadas as disposições anteriores, relativas à matéria do presente decreto-lei.

Rio de Janeiro, 22 de janeiro de 1942, $121^{\circ}$ da Independência e $54^{\circ}$ da República.

Getulio Vargas.

Gustavo Capanema.

Alexandre Marcondes Filho.

B) DECRETO-LEI № 4.073, DE 30 DE JANEIRO DE 1942

(LEI ORGÂNICA DO ENSINO INDUSTRIAL)

TÍTULO IV

DAS ESCOLAS ARTESANAIS E DAS ESCOLAS DE APRENDIZAGEM CAPÍTULO I

DAS ESCOLAS ARTESANAIS

\section{$\left({ }^{\star * \star}\right)$ \\ CAPÍTULO II \\ DAS ESCOLAS DE APRENDIZAGEM}

Art. 67. O ensino industrial das escolas de aprendizagem será organizado e funcionará, em todo o pais, com observância das seguintes prescrições:

I. O ensino dos ofícios, cuja execução exija formação profissional, constituí obrigação dos empregadores para com os aprendizes, seus empregados.

II. Os empregadores deverão, permanentemente, manter aprendizes, a seu serviço, em atividades cujo exercício exija formação profissional.

III. As escolas de aprendizagem serão administradas, cada qual separadamente, pelos próprios estabelecimentos industriais a que pertençam, ou por serviços, de âmbito local, regional ou nacional, a que se subordinem as escolas de aprendizagem de mais de um estabelecimento industrial.

IV. As escolas de aprendizagem serão localizadas nos estabelecimentos industriais a cujos aprendizes se destinem, ou na sua proximidade.

V. O ensino será dado dentro do horário normal de trabalho dos aprendizes, sem prejuízo de salário para estes. 
VI. Os cursos de aprendizagem terão a duração de um, dois, três ou quatro anos.

VII. Os cursos de aprendizagem abrangerão disciplinas de cultura geral e de cultura técnica, e ainda as práticas educativas que for possível, em cada caso, ministrar.

VIII. Preparação primária suficiente, e aptidão física e mental necessária ao estudo do ofício escolhido são condições exigíveis do aprendiz para matrícula nas escolas de aprendizagem.

IX. A habilitação dependerá de freqüência às aulas, e de notas suficientes nos exercícios e exames escolares.

X. A conclusão de um curso de aprendizagem dará direito ao respectivo certificado de habilitação.

$\mathrm{XI}$. Os professores estarão sujeitos a prévia inscrição, mediante prova de capacidade, no registro competente do Ministério da Educação.

XII. As escolas de aprendizagem darão cursos extraordinários, para trabalhadores que não estejam recebendo aprendizagem. Esses cursos, conquanto não incluídos nas secções formadas pelos cursos de aprendizagem, versarão sobre os seus assuntos.

Art. 68. O Ministério da Educação fixará as diretrizes pedagógicas do ensino dos cursos de aprendizagem de todo o país, organizado e mantido pela iniciativa particular, e sobre ele exercerá a necessária inspeção.

Art. 69. Aos poderes públicos cabem, com relação à aprendizagem nos estabelecimentos industriais oficiais, os mesmos deveres por esta lei atribuídos aos empregadores.

Parágrafo único. A aprendizagem, de que trata este artigo, terá regulamentação especial, observados, quanto à organização e ao regime, as prescrições do art. 67 desta lei.

\section{C) DECRETO-LEI № 4.936 - DE 7 DE NOVEMBRO DE 1942}

Amplia o âmbito de ação do Serviço Nacional de Aprendizagem dos Industriários, e dá outras providências.

Art. 1 O Serviço Nacional de aprendizagem dos Industriários (SENAI), criado pelo decreto-lei ํㅜ 4.048, de 22 de janeiro de 1942, passa a denominar-se Serviço Nacional de Aprendizagem Industrial (SENAI).

Art. 2o O Serviço Nacional de Aprendizagem Industrial deverá organizar e administrar escolas de aprendizagem não sòmente para trabalhadores industriários, mas também para trabalhadores dos transportes, das comunicações e da pesca. 
Parágrafo único. Tôdas as escolas de aprendizagem ministraram ensino de continuação e de aperfeiçoamento e especialização.

Art. 3ำ A obrigação decorrente do disposto nos arts. 4 e 6을 do decreto-lei $n^{\circ}$ 4.048, de 22 de janeiro de 1942, se estende às empresas de transportes de comunicações e de pesca, e é exigível a partir de 1ำ de janeiro de 1943.

$\S 1^{\circ} \mathrm{A}$ arrecadação das contribuições, a que ficam obrigadas essas empresas, será feita pelos institutos de previdências ou caixas de aposentadoria e pensões a que elas estiverem filiadas, pondo-se o produto à disposição do Serviço Nacional de Aprendizagem Industrial.

$\S 2^{\circ}$ Vigorará, com relação ao ensino industrial das emprêsas de transportes, de comunicações e de pesca, o disposto no $\S 3^{\circ}$ do art. $4^{\circ}$ do decreto-lei $n^{\circ}$ 4.048, de 22 de janeiro de 1942.

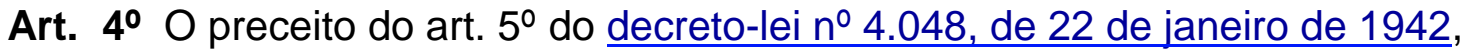
se aplica às emprêsas de transportes, de comunicações e de pesca.

Art. 5 A isenção de que trata 0 art. 50 do decreto-lei no 4.048, de 22 de janeiro de 1942, dependerá, em cada caso, da realização de acôrdo celebrado entre o estabelecimento industrial interessado e o Serviço Nacional de aprendizagem Industrial. De têrmo dêsse acôrdo constarão, circunstanciadamente, as obrigações atribuídas ao estabelecimento industrial relativamente à organização e funcionamento da sua escola ou sistema de escola de Aprendizagem, e cuja inobservância importe rescisão.

Art. 60 Os estabelecimentos industriais, enquadrados na Confederação Nacional da Indústria, mas não filiados ao Instituto de Aposentadoria e Pensões dos Industriários, recolherão as contribuições devidas na forma dos artigos $4^{\circ}$ e $6^{\circ}$ do decreto-lei $n^{\circ} 4.048$, de 22 de janeiro de 1942, por meio das caixas de aposentadoria e pensões a que estiverem filiados.

Art. $7^{\circ}$ Aplicam-se às emprêsas de transportes, de comunicações e de pesca as disposições do decreto-lei no 4.481, de 16 de julho de 1942.

Art. 8 As atribuições conferidas ao Instituto de Aposentadoria e Pensões dos Industriários pelo decreto-lei no 4.481, de 16 de julho de 1942, caberão, quanto aos estabelecimentos industriais que não the sejam filiados ao competente instituto de previdência ou caixa de aposentadoria e pensões.

Art. 9o Êste decreto-lei entrará em vigor na data de sua publicação.

Art. 10. Ficam revogadas as disposições em contrário.

Rio de Janeiro, 7 de novembro de $1942,121^{\circ}$ da Independência e 54ํㅜ da República. 


\section{Getulio Vargas.}

Gustavo Capanema. [Ministro da Educação e Saúde]

João de Mendonça Lima. [Ministro dos Transportes]

Apolonio Sales. [Ministro da Agricultura]

comexang]re Marcondes Filho. [Ministro do Trabalho, Indústria e

D) DECRETO № 494, DE 10 DE JANEIRO DE $1962^{3}$

Aprova o Regimento do Serviço Nacional de Aprendizagem Industrial.

O PRESIDENTE DO CONSELHO DE MINISTROS, usando das atribuições que lhe confere o art. 18, item III, do Ato Adicional à Constituição, decreta:

Art. 1 Fica aprovado o Regimento do Serviço Nacional de Aprendizagem Industrial (SENAI), que com este baixa, assinado pelo Ministro de Estado da Educação e Cultura ${ }^{4}$.

Art. 20 O presente decreto entrará em vigor na data de sua publicação.

Brasília, em 10 de janeiro de 1962, $141^{\circ}$ da Independência e $74^{\circ}$ da República.

Tancredo Neves

Antônio de Oliveira Brito

REGIMENTO DO SERVIÇO NACIONAL DE APRENDIZAGEM INDUSTRIAL - SENAI

(Atualizado pelo Decreto $\mathrm{n}-6.635$, de 5 de novembro de 2008)

\section{CAPÍTULO I}

Dos Objetivos

Art. 1ㅇ O Serviço Nacional de Aprendizagem Industrial (SENAI), organizado e administrado pela Confederação Nacional da Indústria, nos termos do Decreto-lei no 4.048, de 22 de janeiro de 1942, tem por objetivo:

\footnotetext{
${ }^{3}$ Publicado no Diário Oficial da União (DOU), de 11 de janeiro de 1962.

${ }^{4}$ O Decreto $n^{\circ}$ 91.144, de 15 de março de 1985, criou por desdobramento do Ministério da Educação e Cultura, o Ministério da Cultura, alterando a denominação do Ministério da Educação e Cultura para Ministério da Educação. Por meio da Lei n ${ }^{\circ}$ 8.490, de 19 de novembro de 1992, o Ministério da Educação passou a denominar-se Ministério da Educação e do Desporto. A Medida Provisória n ${ }^{\circ}$ 2.216-37, de 31 de agosto de 2001, introduziu na Lei $\mathrm{n}^{\circ}$ 9.649, de 27 de maio de 1998, a nova e atual denominação de Ministério da Educação, que foi mantida pela Lei n ${ }^{\circ} 10.683$, de 28 de maio de 2003.
} 
a) realizar, em escolas instaladas e mantidas pela Instituição, ou sob forma de cooperação, a aprendizagem industrial a que estão obrigadas as empresas de categorias econômicas sob sua jurisdição, nos termos de dispositivo constitucional e da legislação ordinária;

b) assistir os empregadores na elaboração e execução de programas gerais de treinamento do pessoal dos diversos níveis de qualificação, e na realização de aprendizagem metódica ministrada no próprio emprego;

c) proporcionar, aos trabalhadores maiores de 18 anos, a oportunidade de completar, em cursos de curta duração, a formação profissional parcialmente adquirida no local de trabalho;

d) conceder bolsas de estudo e de aperfeiçoamento e a pessoal de direção e a empregados de excepcional valor das empresas contribuintes, bem como a professores, instrutores, administradores e servidores do próprio SENAl;

e) cooperar no desenvolvimento de pesquisas tecnológicas de interesse para a indústria e atividades assemelhadas.

Art. 20 O SENAI funcionará como órgão consultivo do Governo Federal em assuntos relacionados com a formação de trabalhadores da indústria e atividades assemelhadas.

\section{CAPÍTULO II}

\section{Características Civis}

Art. 3 O Serviço Nacional de Aprendizagem Industrial é uma entidade de direito privado, nos termos da lei civil, com sede e foro jurídico na Capital da República, cabendo a sua organização e direção à Confederação Nacional da Indústria.

Parágrafo único. Os dirigentes e prepostos do SENAI, embora responsáveis, administrativa e criminalmente, pelas malversações que cometerem, não respondem individualmente pelas obrigações da entidade.

Art. 4을 $\mathrm{A}$ entidade inscreverá no registro público competente os seus atos constitutivos para todos os efeitos de direito. ${ }^{5}$

Art. $5^{\circ}$ As despesas do SENAI serão custeadas por uma contribuição mensal das empresas das categorias econômicas da indústria, dos transportes ${ }^{6}$, das comunicações e da pesca, nos termos da lei.

\footnotetext{
${ }^{5}$ Os atos constitutivos do SENAI encontram-se arquivados e registrados no $1^{\circ}$ Ofício de Registro Civil das Pessoas Naturais e Jurídicas, localizado em Brasília-DF.

${ }^{6}$ Exceto os transportes: Aquaviário (Lei n ${ }^{\circ} 5.461$, de 25 de junho de 1968), Aeroviário (Decreto-lei no ${ }^{\circ} .305$, de 8 de janeiro de 1974) e Rodoviário (Lei n ${ }^{\circ} 8.706$, de 14 de setembro de 1993).
} 
Art. 6ำ A dívida ativa do Serviço Nacional de Aprendizagem Industrial, decorrente de contribuições, multas ou obrigações contratuais quaisquer, poderá ser cobrada judicialmente pelas instituições arrecadadoras, segundo o rito processual dos executivos fiscais.

Parágrafo único. No caso de cobrança direta pela entidade, a dívida considerar-se-á suficientemente instruída com o levantamento do débito junto à empresa, ou com os comprovantes fornecidos pelos órgãos arrecadadores.

Art. $7^{\circ}$ As ações em que o Serviço Nacional de Aprendizagem Industrial for autor, réu ou interveniente correrão no juízo privativo da Fazenda Pública.

Art. 8ㅇ O SENAI será representado, em juízo ou fora dele, pelo Presidente do Conselho Nacional que, para esse fim, poderá constituir mandatários e procuradores.

Art. 9ㅇ Os bens e serviços do SENAI gozam da mais ampla isenção fiscal. ${ }^{7}$

Art. 10. No que concerne a orçamento e prestação de contas da gestão financeira, a entidade, além das exigências da sua regulamentação específica, está adstrita ao disposto nos arts. 11 e 13 da Lei $n^{\circ} 2.613$, de 23 de dezembro de $1955^{8}$.

$\S 11^{\circ}$ A execução orçamentária dos órgãos nacionais e regionais será de responsabilidade de cada um deles. ${ }^{9}$

$\S 2^{\circ}$ Os órgãos do SENAI destinarão em seus orçamentos anuais parcela de suas receitas líquidas da contribuição compulsória geral à gratuidade em cursos e programas de educação profissional, observadas as diretrizes e regras estabelecidas pelo Conselho Nacional. ${ }^{10}$

$\S 3^{\circ} \mathrm{O}$ montante destinado ao atendimento do disposto no $\S 20$ abrange as despesas de custeio, investimento e gestão voltadas à gratuidade. ${ }^{11}$

Art. 11. Em sua condição de entidade de ensino, o SENAI será fiscalizado pelo Ministério da Educação e Cultura.

Parágrafo único. O Departamento Nacional disponibilizará ao Ministério da Educação informações necessárias ao acompanhamento das ações voltadas

\footnotetext{
${ }^{7}$ Vide o art. 13 da Lei ${ }^{\circ}$ 2.613, de 23 de setembro de 1955, bem como o art. 150, inciso VI, alínea 'c', da Constituição da República Federativa do Brasil de 1988 (CRFB/1988), combinado com o art. 14 do Código Tributário Nacional (CTN).

${ }^{8}$ Onde se lê Lei $n^{\circ} 2.613$, de 23 de dezembro de 1955, leia-se Lei ${ }^{\circ} 2.613$, de 23 de setembro de 1955.

${ }^{9}$ Dispositivo renumerado pelo Decreto $\mathrm{n}^{\circ} 6.635$, de 5 de novembro de 2008, publicado no DOU de 06 de novembro de 2008 (antigo parágrafo único).

${ }^{10}$ Alteração proposta pelo Conselho de Representantes da Confederação Nacional da Indústria (CNI) em reunião realizada em 12 de agosto de 2008 e ratificada pelo Decreto $\mathrm{n}^{\circ} 6.635$, de 5 de novembro de 2008, publicado no DOU de 06 de novembro de 2008.

${ }^{11}$ Vide Nota $n^{\circ} 8$.
} 
à gratuidade, de acordo com método de verificação nacional a ser definido de comum acordo. $^{12}$

Art. 12. O SENAI, afora os casos de dissolução em virtude de lei, poderá cessar a sua atividade por deliberação da Confederação Nacional da Indústria, tomada por três quartas partes dos votos do seu Conselho de Representantes, em reunião especialmente convocada para esse fim.

$\S 1$ 1ㅇ ato extintivo, a requerimento da Confederação Nacional da Indústria, será inscrito no registro público competente, para os efeitos legais.

§ 2ํNa hipótese de dissolução, o patrimônio do SENAI reverterá em favor da Confederação Nacional da Indústria.

Art. 13. O SENAI, sob regime de unidade normativa e de descentralização executiva, atuará em íntima colaboração e articulação com os estabelecimentos contribuintes, através dos respectivos órgãos de classe, visando ao estabelecimento de um sistema nacional de aprendizagem, com uniformidade de objetivos e de planos gerais, adaptável aos meios peculiares às várias regiões do País.

\section{CAPÍTULO III}

Da Organização

Art. 14. O SENAI, para a realização das suas finalidades, corporifica órgãos normativos e órgãos de administração, de âmbito nacional e de âmbito regional.

Art. 15. São órgãos normativos:

a) o Conselho Nacional, com jurisdição em todo o País;

b) os conselhos regionais, com jurisdição nas bases territoriais correspondentes.

Art. 16. São órgãos de administração:

a) o Departamento Nacional, com jurisdição em todo o País;

b) os Departamentos Regionais, com jurisdição nas bases territoriais correspondentes.

\section{CAPÍTULO IV}

Do Conselho Nacional

\footnotetext{
${ }^{12}$ Vide Nota $n^{\circ} 8$.
} 
Art. 17. O Conselho Nacional terá a seguinte composição:

a) presidente da Confederação Nacional da Indústria que será seu presidente nato;

b) dos presidentes dos Conselhos Regionais, na qualidade de presidentes das federações industriais, representando as categorias econômicas da indústria;

c) um representante das categorias econômicas dos transportes ${ }^{13}$, das comunicações e da pesca, designado pelo órgão sindical de grau superior de maior hierarquia e antiguidade, no âmbito nacional;

d) diretor do Departamento Nacional do SENAI; e) diretor da Diretoria de Ensino Industrial do Ministério da Educação e Cultura ${ }^{14}$;

f) um representante do Ministério do Trabalho e Previdência Social ${ }^{15}$, designado por seu titular;

g) seis representantes dos trabalhadores da indústria, e respectivos suplentes, indicados pelas confederações de trabalhadores da indústria e centrais sindicais, que contarem com pelo menos vinte por cento de trabalhadores sindicalizados em relação ao número total de trabalhadores da indústria em âmbito nacional. ${ }^{16}$

$\S 1$ 으 Duas ou mais confederações de trabalhadores da indústria ou duas ou mais centrais sindicais poderão somar seus índices de sindicalização do setor da indústria para atender ao requisito de representatividade estabelecido na alínea " $g$ ". 17

$\S 2^{\circ} \mathrm{A}$ indicação dos representantes dos trabalhadores será proporcional à representatividade das entidades indicantes. ${ }^{18}$

Art. 18. Os membros do Conselho exercerão suas funções individualmente, não lhes sendo permitido fazê-lo através de procuradores.

$\S 1^{0}$ Nos casos de ausência ou impedimentos, os conselheiros serão representados, mediante convocação:

\footnotetext{
${ }^{13}$ Vide Nota $\mathrm{n}^{\mathrm{0}} 4$

${ }^{14}$ Vide Nota $\mathrm{n}^{\mathrm{O}} 2$

${ }^{15} \mathrm{O}$ art. $3^{\circ}$ da Lei ${ }^{0}$ 6.062, de 25 de junho de 1974, alterou a denominação do Ministério do Trabalho e Previdência Social para Ministério do Trabalho e os desvinculou, tendo sido criado o Ministério da Previdência e Assistência Social. A Medida Provisória n ${ }^{0}$ 2.216-37, de 31 de agosto de 2001, introduziu na Lei $n^{\circ}$ 9.649, de 27 de maio de 1998, a nova e atual denominação de Ministério do Trabalho e Emprego, que foi mantida pela Lei $\mathrm{n}^{\mathrm{o}} 10.683$, de 28 de maio de 2003.

${ }^{16}$ Alteração proposta pelo Conselho de Representantes da Confederação Nacional da Indústria (CNI) em reunião ordinária realizada em 10 de março de 2006 e ratificada pelo Decreto $\mathrm{n}^{\circ} 5.727$, de 16 de março de 2006, publicado no DOU, de 17 de março de 2006.

${ }^{17}$ Vide Nota ${ }^{\circ} 14$

${ }^{16}$ Vide Nota ${ }^{\circ} 14$
} 
a) o presidente da Confederação Nacional da Indústria, pelo seu substituto estatutário no órgão de classe;

b) o presidente do conselho regional, pelo suplente designado por este órgão, entre os seus membros;

c) cada trabalhador pelo respectivo suplente que constar do ato que indicou o titular; ${ }^{19}$

d) os demais, por quem for indicado pelo ente representado. ${ }^{20}$ $\S 2^{\circ} \mathrm{O}$ mandato dos Conselheiros indicados nas alíneas "c", "f" e "g" do art. 17 será de dois anos, podendo ser renovado ${ }^{21}$.

$\S 3^{0} \mathrm{O}$ voto, em plenário, dos delegados dos conselhos regionais, como representantes das categorias econômicas da indústria, será contado à razão de um por duzentos mil operários ou fração, existentes na base territorial respectiva, enquanto que o dos demais terá peso unitário.

Art. 19. Compete ao Conselho Nacional:

a) estabelecer as diretrizes gerais que devem ser seguidas pela administração nacional e pelas administrações regionais na educação profissional e tecnológica, incluída a aprendizagem industrial, bem como regulamentar a questão da gratuidade tratada nos $\S \S 20$ e 30 do art. $10 ;{ }^{22}$

b) votar, em verbas globais, o orçamento do Departamento Nacional;

c) autorizar as transferências e as suplementações de dotações solicitadas pelo Diretor do Departamento Nacional, submetendo a matéria à autoridade competente, quando a alteração for superior a $25 \%$ (vinte e cinco por cento) de cada verba;

d) autorizar a compra, ou recebimento por doação, dos imóveis, no Departamento Nacional;

e) autorizar a alienação ou gravame dos imóveis do SENAI;

f) autorizar a alienação dos bens móveis patrimoniais que estejam sob a responsabilidade da administração nacional;

g) homologar os planos de contas do Departamento Nacional e dos Departamentos Regionais, decidindo sobre quaisquer propostas de suas alterações;

\footnotetext{
${ }^{17}$ Vide Nota $\mathrm{n}^{\mathrm{o}} 14$

${ }^{18}$ Vide Nota $\mathrm{n}^{\mathrm{o}} 14$

${ }^{19}$ Vide Nota ${ }^{0} 14$

${ }^{22}$ Vide Nota $n^{\circ} 8$.
} 
h) deliberar sobre prestações de contas anuais do Diretor do Departamento Nacional, as quais deverão ser previamente submetidas ao exame da Comissão de Contas a que se referem os artigos 22 e 23;

i) determinar, depois de verificação realizada por comissão especial que designar, a intervenção na administração regional que descumprir disposição legal, regulamentar, regimental ou resolução plenária, ou em caso de comprovada ineficiência;

j) estabelecer a designação e a forma de funcionamento de delegacias para administrar os serviços da instituição nas unidades políticas onde não haja federação de indústria reconhecida;

k) mediante proposta do Diretor do Departamento Nacional, aprovar os quadros de pessoal, fixar os padrões de vencimentos, o critério e a época de promoções, bem como examinar quaisquer reajustamentos de salários do Departamento Nacional;

I) fixar a remuneração do diretor do Departamento Nacional;

m) fixar as percentagens de aprendizes a serem matriculados pelas empresas, bem como a duração dos cursos;

n) autorizar a realização ou anulação de convênios que impliquem na concessão de isenção de contribuição devida ao SENAI;

o) autorizar a realização de acordos com os órgãos internacionais de assistência técnica, visando à formação de mão-de-obra e ao aperfeiçoamento do pessoal docente e técnico do SENAI e das empresas contribuintes;

p) decidir sobre estudos e planejamentos da formação ou do aperfeiçoamento do pessoal latino-americano, ou de outra procedência, quando decorrentes de acordos com entidades internacionais;

q) autorizar a execução de planos de bolsas de estudo no País ou no estrangeiro, para técnicos das empresas contribuintes, ou do SENAI, a serem custeados, parcial ou totalmente, pela Instituição;

r) autorizar a realização de convênios entre o SENAI e entidades ou escolas de todos os níveis, visando à formação ou ao aperfeiçoamento de mão-deobra industrial;

s) julgar, em instância final, os recursos das decisões das administrações regionais que aplicarem multas e penalidades às empresas infratoras das leis pertinentes ao SENAI;

t) fixar a ajuda de custo e as diárias de seus membros; 
u) deliberar sobre o relatório anual das atividades da Instituição em todo o País;

v) expedir as normas internas de seu funcionamento, alterando-as quando julgar conveniente;

x) decidir, em última instância, as questões de ordem geral do interesse do SENAI, ex ofício ou que Ihe forem submetidas pelo Departamento Nacional e pelas administrações regionais;

z) dar solução aos casos omissos.

Art. 20. As despesas com o funcionamento do Conselho Nacional serão autorizadas pelo seu presidente e correrão à conta de verbas destacadas no orçamento do Departamento Nacional.

Art. 21. O Conselho Nacional, para o desempenho de suas atribuições específicas, disporá de um secretário, de um consultor geral e de um consultor jurídico, além dos assessores técnicos que forem necessários, a juízo do presidente.

Art. 22. O Conselho Nacional designará três (3) dos seus membros para constituírem uma Comissão de Contas que terá a incumbência de fiscalizar a execução orçamentária, bem como a movimentação de fundos do Departamento Nacional e das Delegacias Regionais.

Art. 23. Para o desempenho de suas atribuições a Comissão de Contas disporá de auditores que deverão ser contratados pelo prazo máximo de 18 meses.

$\S 1$ 으 Os auditores não poderão ser contratados por outro período antes de transcorrido o prazo de 2 (dois) anos do término do último contrato.

$\S 2^{\circ}$ Além das atribuições que Ihes forem determinadas pela Comissão, deverão os auditores encaminhar a esta um certificado de revisão e de exatidão das contas do Departamento Nacional e das delegacias regionais.

Art. 24. Compete ao Presidente do Conselho Nacional:

a) fazer cumprir, sob sua responsabilidade administrativa, todas as resoluções emanadas do Conselho Nacional;

b) fixar os níveis máximos de vencimentos dos Diretores e Delegados Regionais;

c) deliberar, mediante proposta do Diretor do Departamento Nacional, sobre a escolha dos nomes dos bolsistas da indústria e do SENAI com planos de estudo no estrangeiro; 
d) exercer, no interregno das sessões, ad-referendum do Conselho Nacional, as atribuições indicadas nas alíneas "c", "o", "p" e "r" do art. 19.

Art. 25. O Conselho reunir-se-á, ordinariamente, duas vezes por ano e, extraordinariamente, sempre que convocado pelo presidente ou por dois terços de seus membros.

$\S 1^{\circ}$ O Conselho se instalará com a presença de um terço dos seus membros, sendo, porém, necessário o comparecimento da maioria absoluta para as deliberações.

$\S 2^{\circ}$ As decisões serão tomadas por maioria de sufrágios, cabendo ao presidente o voto de qualidade nos empates verificados.

Art. 26. O Conselho, no exercício de suas atribuições, será coadjuvado, no que for preciso, pelo Departamento Nacional, que Ihe ministrará, durante as sessões, assistência técnica necessária.

Art. 27. O Conselheiro manterá contato permanente com a Confederação Nacional da Indústria, na troca e coleta de elementos relativos ao ensino industrial, autorizando, quando necessário, a celebração de acordos e convênios.

\section{CAPÍTULO V}

Do Departamento Nacional

Art. 28. Compete ao Departamento Nacional:

a) promover e realizar estudos e levantamentos de mão-de-obra;

b) colaborar com os departamentos regionais na elaboração de planos de escolas e cursos;

c) assistir os Departamentos Regionais na implantação de cursos novos e no aperfeiçoamento dos existentes;

d) elaborar programas, séries metódicas, livros e material didático, diretamente ou em colaboração com os departamentos regionais e editá-los quando conveniente;

e) estabelecer critérios e meios para avaliação do rendimento escolar;

f) assistir os Departamentos Regionais no planejamento de edificações, bem como no exame e escolha de equipamentos escolares;

g) colaborar com as empresas contribuintes no estudo de planos de treinamento de mão-de-obra no próprio emprego, promovendo entendimentos entre os Departamentos Regionais e os empregados, para a realização; 
h) orientar os serviços orçamentários e contábeis dos Departamentos Regionais, visando à sua uniformidade;

i) verificar, quando determinado pelo Conselho Nacional, a execução orçamentária e as contas dos Departamentos Regionais;

j) submeter ao Conselho Nacional o plano de contas do Departamento Nacional e dos Departamentos Regionais;

k) fixar as diretrizes para a estatística relativa à aprendizagem ministrada pelo SENAI e pelas empresas, receber os dados coletados pelos Departamentos Regionais e realizar as análises necessárias;

I) promover reuniões de diretores, chefes de serviços, professores, instrutores, supervisores e técnicos dos Departamentos Regionais e das empresas, para exame de problema de formação e treinamento de mão-de-obra;

m) elaborar relatório anual sobre a formação e treinamento de mão-de-obra no SENAl e nas empresas;

n) organizar ou realizar cursos de aperfeiçoamento e de especialização do pessoal docente, técnico e administrativo do SENAl;

o) realizar estudos e pesquisas de natureza técnica e administrativa, de interesse da Instituição;

p) opinar sobre os recursos interpostos sobre penas aplicadas pelos Departamentos Regionais aos infratores das leis pertinentes do SENAI.

q) submeter à aprovação do Conselho Nacional proposta de regras de desempenho a ser seguida pelos órgãos do SENAI nas ações de gratuidade, cujo teor deverá observar o princípio federativo, as diretrizes estratégicas da entidade e o controle com base em indicadores qualitativos e quantitativos; ${ }^{23}$

r) acompanhar e avaliar o cumprimento das regras de desempenho e das metas físicas e financeiras relativas às ações de gratuidade. ${ }^{24}$

Art. 29. O Departamento Nacional será dirigido por um diretor, nomeado e demissível ad-nutum pelo presidente do Conselho Nacional, devendo a escolha recair em pessoa com formação universitária e conhecimentos especializados de ensino industrial.

Parágrafo único. O Diretor do Departamento Nacional será substituído, em seus impedimentos, por pessoa designada pelo presidente do Conselho Nacional.

\footnotetext{
${ }^{23}$ Vide Nota ${ }^{\circ} 8$.

${ }^{24}$ Vide Nota ${ }^{\circ} 8$.
} 
Art. 30. Ao Diretor do Departamento Nacional compete:

a) fazer cumprir, sob sua responsabilidade funcional, todas as resoluções emanadas do Conselho e encaminhadas pelo seu presidente;

b) organizar, superintender e fiscalizar, direta ou indiretamente, todos os serviços a cargo do Departamento Nacional, expedindo ordens, instruções de serviço e portarias praticando todos os atos necessários ao pleno exercício de suas funções;

c) apresentar ao Conselho Nacional as propostas orçamentárias, os balanços e as prestações de contas anuais do Departamento Nacional, encaminhando posteriormente essa documentação ao órgão competente;

d) apresentar, anualmente, ao Conselho Nacional o relatório das atividades do Departamento Nacional;

e) organizar e submeter à aprovação, do Conselho Nacional o quadro do pessoal do Departamento Nacional, dentro dos limites orçamentários;

f) admitir, promover e demitir os serventuários do Departamento Nacional, mediante aprovação do presidente do Conselho Nacional;

g) fixar as ajudas de custo e diárias de seus servidores mediante aprovação do presidente do Conselho Nacional;

h) conceder férias, licenças e aplicar penas disciplinares aos serventuários do Departamento Nacional, assim como resolver sobre a movimentação do pessoal, dentro dos quadros funcionais, inclusive no que respeita ao provimento dos cargos e funções de confiança;

i) submeter à apreciação do Conselho Nacional proposições sobre assuntos que, fora da alçada da decisão do Diretor, sejam de interesse da Instituição;

j) abrir contas em bancos e movimentar os fundos do Departamento Nacional, assinando os cheques com o presidente do Conselho Nacional, ou com pessoa por este designada, respeitadas as normas previstas no art. 54;

k) cumprir qualquer missão de natureza técnica ou funcional que the seja atribuída pelo Conselho Nacional ou pelo seu presidente;

I) conceder bolsas de estudo, respeitado o disposto na letra "q" do art. 19 e na letra "c" do art. 24;

m) delegar competência a chefes de serviço do Departamento Nacional, mediante aprovação do presidente do Conselho Nacional.

\section{CAPÍTULO VI}




\section{Órgãos Regionais}

Art. 31. No Distrito Federal, nos Estados e nos Territórios em que houver federação de indústrias oficialmente reconhecida e filiada ao órgão superior da classe será constituído um Conselho Regional e instalado um Departamento Regional do SENAI, com jurisdição na base territorial respectiva.

\section{SEÇÃO I}

Conselhos Regionais

Art. 32. Os Conselhos Regionais se comporão dos seguintes membros:

a) do presidente da federação de indústrias, que será o seu presidente nato, ou seu representante;

b) de quatro delegados das atividades industriais, escolhidos pelo Conselho de Representantes da entidade federativa, ${ }^{25}$

c) de um delegado das categorias econômicas dos transportes ${ }^{26}$, das comunicações e da pesca, escolhido pela associação sindical de maior hierarquia e antiguidade existente na base territorial respectiva;

d) do diretor do Departamento Regional;

e) de um representante do Ministério do Trabalho e Previdência Social ${ }^{27}$, designado pelo titular da pasta;

f) de um representante do Ministério da Educação e Cultura ${ }^{28}$, designado pelo seu titular;

g) de um representante, e respectivo suplente, dos trabalhadores da indústria, indicado pela organização dos trabalhadores mais representativa da região. ${ }^{29}$ Vide Nota no 14.

Parágrafo único. Os representantes a que se referem as alíneas "b", "c" e "g" exercerão o mandato por dois anos, sendo permitida a recondução de dois terços da representação nos casos das alíneas "b" e "c".

Art. 33. Ocuparão os lugares dos Conselheiros Regionais, nas suas faltas e impedimentos, os substitutos estatutários, ou os suplentes designados.

\footnotetext{
${ }^{25}$ Vide Nota $\mathrm{n}^{\mathrm{o}} 14$

${ }^{26}$ Vide Nota $n^{\circ} 4$.

${ }^{27}$ Vide Nota $n^{\circ} 13$.

${ }^{28}$ Vide Nota $n^{\circ} 2$.

${ }^{29}$ Vide Nota $n^{\circ} 14$

${ }^{30}$ Vide Nota $n^{\circ} 14$
} 
Art. 34. Compete a cada Conselho Regional:

a) votar, em verbas globais, o orçamento do Departamento Regional, e submetê-lo ao poder competente;

b) autorizar as transferências e as suplementações de dotações solicitadas pelo diretor do Departamento Regional, encaminhando o assunto à aprovação da autoridade competente quando as alterações excederem de $25 \%$ (vinte e cinco por cento) de cada verba;

c) apreciar periodicamente a execução orçamentária na região;

d) examinar anualmente o inventário de bens a cargo da administração regional;

e) deliberar sobre a prestação de contas anual do Departamento Regional, a qual deverá ser previamente submetida ao exame de uma Comissão de Contas a que se referem os artigos 35 e 36 ;

f) resolver sobre os contratos de construção de escolas na região;

g) autorizar a compra, ou o recebimento por doação, de bens imóveis;

h) dar parecer sobre a alienação ou gravame de bens imóveis e encaminhá-la à decisão do Conselho Nacional;

i) autorizar a alienação de bens móveis patrimoniais que estejam sob a responsabilidade da administração regional;

j) deliberar sobre o relatório anual do Departamento Regional, remetendo uma via dele ao Departamento Nacional, em tempo útil, para o preparo do relatório anual deste órgão;

k) desempenhar as incumbências que the forem delegadas pelo Conselho Nacional;

I) mediante proposta do Diretor do Departamento Regional, deliberar sobre os quadros do pessoal, fixar os padrões de vencimentos, determinar o critério e a época das promoções, bem como examinar quaisquer reajustamentos de salários;

m) fixar a remuneração do diretor do Departamento Regional dentro dos níveis estabelecidos pelo presidente do Conselho Nacional;

n) autorizar o Departamento Regional a aplicar as penas previstas na legislação vigente aos empregadores que não cumprirem os dispositivos legais, regulamentares e regimentais relativos ao SENAl;

o) estabelecer as normas internas do seu funcionamento; 
p) estabelecer a cédula de presença dos conselheiros, não podendo esta exceder, mensalmente, o valor do salário mínimo mensal da região;

q) autorizar a concessão de contribuições à federação de industriais de sua base territorial até o limite de um por cento da receita regional.

Art. 35. O Conselho Regional designará 3 (três) dos seus membros para constituírem uma Comissão de Contas que terá a incumbência de fiscalizar a execução orçamentária, bem como a movimentação de fundos do Departamento Regional.

Art. 36. Para o desempenho de suas atribuições a Comissão de Contas disporá de auditores que deverão ser contratados pelo prazo máximo de 18 (dezoito) meses.

$\S 1$ 응 Os auditores não poderão ser contratados por outro período antes de transcorrido o prazo de 2 (dois) anos do término do último contrato.

$\S$ 2ำ Além das atribuições que Ihes forem determinadas pela Comissão de Contas deverão os auditores encaminhar a esta um certificado de revisão e de exatidão das contas.

Art. 37. Compete aos presidentes dos conselhos regionais:

a) dirigir o plenário do Conselho Regional;

b) fazer cumprir, sob suas responsabilidades administrativas, todas as resoluções emanadas do Conselho Regional.

Art. 38. Os conselhos regionais reunir-se-ão, ordinariamente, uma vez por mês e, extraordinariamente, quando convocados pelo presidente ou por dois terços de seus membros, aplicando-se-lhes, quanto ao funcionamento, 0 disposto no artigo 25 e seus parágrafos 1 e 2 .

\section{SEÇÃO II}

\section{Dos Departamentos Regionais}

Art. 39. Cada Departamento Regional será dirigido por um diretor nomeado, mediante entendimento com o presidente do Conselho Regional, pelo presidente do Conselho Nacional e por este demissível "ad-nutum", devendo a escolha recair em pessoa que, além de ter formação universitária, possua conhecimentos especializados de ensino industrial, com experiência no magistério ou na administração dessa modalidade de ensino.

Parágrafo único. O Diretor Regional será substituído, nos seus impedimentos, por quem for designado pelo presidente do Conselho Regional, dentro do quadro de serventuários do Departamento Regional. 
Art. 40. Compete a cada Departamento Regional:

a) submeter ao Conselho Regional o plano para a realização da aprendizagem na região;

b) estabelecer, mediante aprovação do Conselho Regional, a localização e os planos de instalação de escolas, cursos de aprendizagem e cursos extraordinários para operários maiores de 18 anos;

c) cooperar, com as empresas contribuintes, na realização da aprendizagem e treinamento de mão-de-obra no próprio emprego, elaborando planos e programas;

d) complementar, quando conveniente, o treinamento de pessoal realizado nas empresas contribuintes;

e) elaborar programas, séries metódicas, livros e material didático, sempre que possível em colaboração com o Departamento Nacional;

f) cuidar do aperfeiçoamento do seu pessoal docente, técnico e administrativo, articulando-se, para isso, com o Departamento Nacional;

g) verificar o rendimento escolar dos diversos cursos e adotar medidas para o seu aprimoramento, de maneira a assegurar a eficiência do ensino ministrado nas escolas do SENAI, na região;

h) fazer realizar as provas de habilitação para a concessão de certificados de aprendizagem e de cartas de ofícios;

i) expedir certificados de aproveitamento, certificados de aprendizagem e cartas de ofícios;

j) elaborar a proposta orçamentária, em verbas globais, e preparar a prestação de contas anual do Departamento Regional;

k) manter em dia e em ordem a escrituração contábil, adotando o plano de contas aprovado pelo Conselho Nacional;

I) aplicar as penas previstas na legislação vigente aos empregadores que não cumprirem os dispositivos legais, regulamentares e regimentais relativos ao SENAI, obedecido o disposto na letra " $n$ " do art. 34;

m) elaborar o relatório anual das atividades do Departamento Regional;

Art. 41. Compete ao Diretor de cada Departamento Regional;

a) fazer cumprir, sob sua responsabilidade funcional, todas as resoluções emanadas do Conselho Regional e encaminhadas pelo seu presidente; 
b) organizar, superintender e fiscalizar, direta ou indiretamente, todos os serviços do Departamento Regional, expedindo ordens, instruções de serviço e portarias e praticando todos os atos necessários ao pleno exercício de suas funções;

c) apresentar ao Conselho Regional as propostas orçamentárias e as prestações de contas anuais do Departamento Regional, encaminhando-as, posteriormente, ao órgão competente;

d) apresentar, anualmente, ao Conselho Regional, o relatório das atividades do Departamento Regional;

e) organizar e submeter, ao Conselho Regional, o quadro de pessoal do Departamento Regional, dentro dos limites orçamentários;

f) admitir, promover e demitir os serventuários do Departamento Regional, mediante aprovação do presidente do Conselho Regional;

g) conceder férias, licenças e aplicar penas disciplinares aos serventuários do Departamento Regional, assim como resolver sobre a movimentação do pessoal, dentro dos quadros funcionais, inclusive no que respeita ao provimento dos cargos e funções de confiança;

h) fixar as ajudas de custo e diárias de seus servidores mediante aprovação do Presidente do Conselho Regional;

i) abrir contas e movimentar os fundos do Departamento Regional, assinando os cheques com o Presidente do Conselho Regional ou pessoa por este designada, respeitadas as normas previstas no art. 54 .

\section{CAPÍTULO VII}

Do Pessoal do SENAI

Art. 42. O exercício de todas as funções do Serviço Nacional de Aprendizagem Industrial dependerá de provas de habilitação ou de seleção, salvo os contratos especiais.

Art. 43. O Estatuto dos Servidores do SENAl estabelecerá os direitos e deveres dos funcionários da entidade em todo o País.

Art. 44. Os servidores do SENAI estão sujeitos à legislação do trabalho e da previdência social, considerando-se o Serviço Nacional de Aprendizagem Industrial, na sua qualidade de entidade civil de direito privado, como empresa empregadora. 
Parágrafo único. Os servidores do SENAI serão segurados obrigatórios do Instituto de Aposentadoria e Pensões dos Industriários. ${ }^{31}$

\section{CAPÍTULO VIII}

\section{Dos Recursos do SENAI}

Art. 45. Constituem receita do SENAI:

a) as contribuições previstas em lei; ${ }^{32}$ b) as doações e legados; c) as subvenções;

d) as multas arrecadadas por infração de dispositivos legais e regulamentares;

e) rendas oriundas de prestações de serviços e mutações patrimoniais, inclusive as de locação de bens de qualquer natureza;

f) as rendas eventuais.

Art. 46. A arrecadação das contribuições devidas ao SENAI será feita pelo Instituto ou Caixa de Aposentadoria e Pensões $^{33}$ a que estiver filiada a empresa contribuinte, concomitantemente com a das contribuições de previdência social, quer na fase de cobrança administrativa, quer na de cobrança judicial, correndo as ações daí porventura resultantes no mesmo foro da instituição arrecadadora.

Art. 47. A título de indenização pelas despesas com a arrecadação feita em favor do SENAI, as instituições de previdência social ${ }^{34}$ deduzirão do montante arrecadado:

a) $1 \%$ (hum cento), nos recolhimentos por via administrativa;

b) importância a ser fixada em convênio, quando se tornar necessária a cobrança judicial.

Parágrafo único. Os órgãos arrecadadores se reembolsarão, ainda, dos gastos efetuados com impressos e com serviços de terceiros, na efetivação dos recolhimentos destinados ao SENAI ${ }^{35}$.

\footnotetext{
${ }^{31}$ O Decreto-lei ${ }^{\circ}$ 72, de 21 de novembro de 1966, unificou os Institutos de Aposentadoria e Pensões sob a denominação de Instituto Nacional de Previdência Social (INPS). A Lei n ${ }^{\circ}$ 8.029, de 12 de abril de 1990, art. 17, mediante a fusão do Instituto de Administração da Previdência e Assistência Social (IAPAS) com o INPS, criou o Instituto Nacional do Seguro Social (INSS).

${ }^{32}$ Pelo art. $1^{\circ}$ do Decreto-lei $n^{\circ}$ 6.246, de 5 de fevereiro de 1944, a contribuição destinada à montagem e ao custeio das escolas de aprendizagem, a cargo do SENAI, passou a ser arrecadada na base de um por cento sobre o montante da remuneração paga pelos estabelecimentos contribuintes a todos os seus empregados.

${ }^{33} \mathrm{O}$ art. $3^{\circ}$ da Lei no 11.457, de 16 de março de 2007, indicou a Secretaria da Receita Federal do Brasil como órgão responsável pela arrecadação e fiscalização da contribuição de terceiros.

${ }^{34}$ Vide Nota $\mathrm{n}^{\mathrm{o}} 31$.
} 
Art. 48. Deduzidas as comissões a que se refere o artigo antecedente, as instituições de previdência ${ }^{36}$ entregarão ao SENAI, até o dia 20 de cada mês, as importâncias arrecadadas no mês anterior, de acordo com a seguinte distribuição:

a) ao Departamento Nacional será entregue a importância correspondente à contribuição adicional e à quota de 15\% sobre a contribuição geral;

b) aos Departamentos Regionais será entregue a importância correspondente a $85 \%$ da contribuição geral.

Art. 49. A entrega direta da arrecadação ao Departamento Nacional e aos Departamentos Regionais será feita pelas instituições de previdência ${ }^{37}$ mediante duodécimos, que deverão ser reajustados periodicamente pelo Departamento Nacional do SENAI.

$\S 1$ 을 De três em três meses, proceder-se-á a acertos, entregando- se ao Departamento Nacional a importância correspondente às diferenças entre a arrecadação efetivamente realizada e os duodécimos entregues aos diversos Departamentos. ${ }^{38}$

$\S 2^{\circ}$ Feitas as necessárias deduções, o Departamento Nacional distribuirá aos Departamentos Regionais os saldos que Ihes couberem em conseqüência dos acertos indicados no parágrafo anterior.

Art. 50. Visando ao atendimento de situações especiais, determinadas empresas poderão recolher as suas contribuições diretamente aos cofres do SENAI.

Parágrafo único. O Departamento a cujos cofres forem recolhidas essas contribuições providenciará, até o dia 20 do mês subseqüente, a sua distribuição de maneira idêntica ao que estipulam as letras "a" e "b" do art. 48.

Art. 51. A quota destinada às despesas de caráter geral, prevista na legislação vigente e calculada sobre a receita geral do SENAI, será assim distribuída:

a) $5 \%$ da receita da contribuição geral para as despesas de custeio da Administração Nacional do SENAl;

\footnotetext{
${ }^{35}$ Pelo art. $3^{\circ}$, § 10 da Lei n ${ }^{\circ} 11.457$, de 16 de março de 2007, a remuneração devida à Secretaria da Receita Federal do Brasil será de 3,5\% (três inteiros e cinco décimos por cento) do montante arrecadado.

${ }^{36}$ Vide Nota $n^{\circ} 31$.

${ }^{37}$ Vide Nota $\mathrm{n}^{\mathrm{o}} 31$.

${ }^{38}$ Atualmente o assunto é tratado pelo Manual GFIP/SEFIP 8.4, aprovado pela Instrução Normativa RFB $n^{\circ}$ 880, de 16 de outubro de 2008 e pela Circular CAIXA n ${ }^{\circ}$ 451/2008, de 13 de outubro de 2008.
} 
b) $4 \%$ da receita da contribuição geral para o auxílio às escolas ou cursos em regiões onde a arrecadação seja insuficiente para a manutenção do mínimo de ensino julgado necessário; ${ }^{39}$

c) $4 \%$ destinados a planos de ampliação de escolas e cursos ou criação de centros de treinamentos, nas regiões Norte e Nordeste do País, ou ainda a concessão de bolsas de estudo a alunos desses centros, mediante aprovação do Conselho Nacional; ${ }^{40}$

d) $2 \%$ para a administração superior, a cargo da Confederação Nacional da Indústria.

Art. 52. Os recursos previstos na alínea "b" do art. 51 serão distribuídos às regiões interessadas levando-se em conta o número de operários de cada uma e a média dos salários- mínimos das sedes das escolas, por uma comissão de cinco membros do Conselho Nacional.

Art. 53. A contribuição adicional prevista em lei destina-se:

a) à formação, aperfeiçoamento ou especialização, inclusive por meio de bolsas de estudo, do pessoal das empresas que pagam esta contribuição;

b) ao aperfeiçoamento ou especialização de pessoal técnico, docente e administradores de ensino do SENAI, sob a forma de bolsas, de cursos e estágios;

c) à montagem de laboratórios de pesquisa para fins de ensino.

Art. 54. O depósito dos recursos do SENAI será obrigatoriamente feito no Banco do Brasil ou em bancos particulares aprovados pelo Conselho Nacional, no caso do Departamento Nacional, e pelos Conselhos Regionais, no caso dos Departamentos Regionais. ${ }^{41}$

$\S 11^{0}$ Nenhum depósito poderá ser feito em estabelecimento bancário com capital realizado inferior a dez mil vezes o valor do maior salário-mínimo em vigor no País.

$\S 2^{0}$ Os depósitos em cada estabelecimento bancário não poderão exceder a $1 \%$ (hum por cento) do valor dos depósitos à vista e à prazo, constantes dos respectivos balancetes.

\section{CAPÍTULO IX}

\footnotetext{
${ }^{39}$ Vide Regulamento do Fundo de Auxílio a Regiões Deficitárias (FARD), instituído pelo Conselho Nacional do SENAI, por meio do item XIV da Resolução n ${ }^{\circ}$ 145, de março de 1990, com base na Proposição ${ }^{\circ}{ }^{\circ}$ 15, de março de 1990.

${ }^{40}$ Vide Nota ${ }^{\circ} 37$.

${ }^{41}$ Pelo art. $1^{\circ}$ do Decreto-lei no 151 , de 9 de fevereiro de 1967, as disponibilidades do SENAI deverão ser mantidas em depósito exclusivamente no Banco do Brasil e Caixa Econômica Federal.
} 
Do Orçamento e da Prestação de Contas

Art. 55. O orçamento dos Departamentos Regionais, devidamente aprovado pelos Conselhos Regionais, e os orçamentos do Departamento Nacional e das Delegacias Regionais, aprovados pelo Conselho Nacional, acompanhados do resumo geral dos orçamentos da Entidade, serão encaminhados, pelo Presidente do Conselho Nacional, à Presidência da República, nos termos dos arts. 11 e 13 da Lei no 2.613, de 23 de setembro de $1955 .{ }^{42}$

$\S 1$ 1 Os Departamentos Regionais deverão ter os seus orçamentos aprovados pelos Conselhos Regionais em prazo que permita a sua entrega, até o dia 30 de setembro de cada ano, ao Departamento Nacional, para que possam ser remetidos à Presidência da República.

$\S 2$ 응 orçamento deverá apresentar as previsões da receita e as aplicações da despesa, em verbas globais.

$\S$ 3ํㅡ Até 31 de agosto de cada ano, o Departamento Nacional dará conhecimento às administrações regionais das previsões de receitas que lhes serão atribuídas para o exercício futuro.

$\S 4^{\circ}$ O Departamento Nacional organizará, até 30 de setembro de cada ano, o seu próprio orçamento e o das Delegacias Regionais e, até 31 de outubro de cada ano, um resumo geral dos orçamentos da Entidade, referente ao exercício futuro, para serem submetidos, os primeiros à aprovação do Conselho Nacional, e, os dos Regionais, para simples conhecimento desse Conselho, no correr do mês de novembro.

Art. 56. Os balanços financeiros, econômico e patrimonial, bem como a execução orçamentária do Departamento Nacional e das Delegacias Regionais, para efeitos de prestação de contas, deverão ser submetidos ao Conselho Nacional, órgão próprio de controle e tomada de contas do Departamento Nacional e das Delegacias Regionais, na primeira quinzena de março, para seu pronunciamento, e encaminhados, em seguida, ao Tribunal de Contas da União, até 31 desse mês, de acordo com os arts. 11 e 13 da lei citada.

$\S 1^{\circ}$ 을 prestações de contas dos Departamentos Regionais, sob a responsabilidade de seus titulares, devidamente aprovadas pelos respectivos Conselhos Regionais, órgãos próprios de controle e tomada de contas regionais, deverão ser encaminhadas ao Tribunal de Contas da União, pelos Presidentes dos respectivos Conselhos Regionais, até o dia 31 de março.

\footnotetext{
42 O Presidente da República por meio do Decreto no 715, de 29 de dezembro de 1992, alterado pelo Decreto no 3.334, de 11 de janeiro de 2000, delegou competência ao Ministro de Estado do Trabalho e Emprego para aprovar o orçamento geral do SENAI.
} 
$\S 2^{\circ}$ As prestações de contas dos Departamentos e Delegacias Regionais e a do Departamento Nacional deverão observar as instruções do Tribunal de Contas da União.

Art. 57. O Departamento Nacional complementará com instruções próprias a organização dos orçamentos e a prestação de contas, no âmbito nacional, como no regional.

Art. 58. As retificações orçamentárias, no correr do exercício, se processarão, se necessário, no segundo semestre, até o mês de setembro e obedecerão aos mesmos princípios da elaboração do orçamento.

\section{CAPÍTULO $X$}

Disposições Gerais

Art. 59. O Serviço Nacional de Aprendizagem Industrial manterá relações permanentes com a Confederação Nacional da Indústria, no âmbito Nacional, e com as federações de indústrias, no âmbito regional, colimando um melhor rendimento dos objetivos comuns do ensino industrial, da ordem e da paz social.

Art. 60. Igual procedimento manterá o SENAI com o Serviço Social da Indústria (SESI), no atendimento de idênticas finalidades.

Art. 61. O disposto nos dois artigos anteriores poderá regular- se em convênio entre as entidades interessadas.

Art. 62. Cabe à Confederação Nacional da Indústria encaminhar ao Ministro de Educação e Cultura ${ }^{43}$ proposta de alteração do presente regimento.

\section{CAPÍTULO XI}

Das Disposições Transitórias

Art. 63. O pessoal lotado no quadro do Conselho Nacional, com exceção dos servidores aludidos no art. 21, será distribuído pelos órgãos do Departamento Nacional.

Art. 64. O orçamento e a escrita do Conselho Nacional referente ao exercício de 1962 ficam incorporados ao orçamento e à escrita do Departamento Nacional.

Art. 65. As alterações administrativas, orçamentárias e contábeis decorrentes da entrada em vigor deste Regimento serão procedidas imediatamente após a sua aprovação.

\footnotetext{
${ }^{43}$ Vide Nota $n^{\circ} 2$.
} 
Art. 66. Fica autorizada a utilização de recursos dos diversos departamentos e delegacias do SENAI até o limite de $\operatorname{Cr} \$ 200.000 .000,00$ (duzentos milhões de cruzeiros), dentro do prazo de 3 (três) anos, para a realização dos planos de construção e instalação dos centros de treinamento previstos na letra "c" do art. 51.

Art. 67. A sede do SENAI permanecerá, em caráter provisório, na Cidade do Rio de Janeiro, transferindo-se para Brasília, Distrito Federal, em época a ser fixada pela Confederação Nacional da Indústria. ${ }^{44}$

Art. 68. O SENAI vinculará, anual e progressivamente, até o ano de 2014, o valor correspondente a dois terços de sua receita líquida da contribuição compulsória geral para vagas gratuitas em cursos e programas de educação profissional. ${ }^{45}$

$\S 1$ ㅇ Para os efeitos deste artigo, entende-se como receita líquida da contribuição compulsória geral do SENAI o valor correspondente a noventa e dois inteiros e cinco décimos por cento da receita bruta da contribuição compulsória geral. ${ }^{46}$

$\S$ 2응 O Departamento Nacional informará aos Departamentos Regionais, anualmente, a estimativa da receita líquida da contribuição compulsória geral do SENAI para o exercício subseqüente, de forma que possam prever em seus orçamentos os recursos vinculados à gratuidade. ${ }^{47}$

$\S$ 3ำ A alocação de recursos para as vagas gratuitas deverá evoluir, anualmente, a partir do patamar atualmente praticado, de acordo com as seguintes projeções médias nacionais: ${ }^{48}$

I - cinqüenta por cento em $2009 ;{ }^{49}$

II - cinqüenta e três por cento em 2010; ${ }^{50}$

III - cinqüenta e seis por cento em 2011,51

IV - cinqüenta e nove por cento em 2012; ${ }^{52}$

$V$ - sessenta e dois por cento em 2013; $\mathrm{e}^{53}$

\footnotetext{
${ }^{44}$ A Resolução no 118, de 25 de março de 1981, do Conselho Nacional, transferiu a sede do SENAI para Brasília-DF.

${ }^{45}$ Vide Nota ${ }^{\circ} 8$

${ }^{46}$ Vide Nota $n^{\circ} 8$

${ }^{47}$ Vide Nota ${ }^{\circ} 8$

${ }^{48}$ Vide Nota ${ }^{\circ} 8$

${ }^{49}$ Vide Nota ${ }^{\circ} 8$

${ }^{50}$ Vide Nota ${ }^{\circ} 8$

${ }^{51}$ Vide Nota ${ }^{\circ} 8$

${ }^{52}$ Vide Nota ${ }^{\circ} 8$
} 
$\mathrm{VI}$ - sessenta e seis inteiros e sessenta e seis centésimos por cento a partir de 2014, equivalente a sessenta e um inteiros e sessenta e seis centésimos por cento da receita bruta da contribuição compulsória geral. ${ }^{54}$

$\S$ 4ㅇ Os Departamentos Regionais deverão submeter ao Departamento Nacional, até o final do ano de 2008, plano de adequação à projeção referida no $\S 3$. 55

$\S 5^{\circ}$ As vagas gratuitas a que se refere este artigo deverão ser destinadas a pessoas de baixa renda, preferencialmente, trabalhador, empregado ou desempregado, matriculado ou que tenha concluído a educação básica. ${ }^{56}$

$\S 6^{0}$ A situação de baixa renda será atestada mediante auto- declaração do postulante. ${ }^{57}$

Art. 69. Fica estabelecida carga horária mínima de cento e sessenta horas para os cursos de educação profissional destinados a formação inicial. ${ }^{58}$

Parágrafo único. Os cursos e programas de formação continuada não estão sujeitos à carga horária mínima prevista no caput, tendo como requisito para ingresso comprovação de formação inicial ou avaliação ou reconhecimento de competências para aproveitamento em prosseguimento de estudos. ${ }^{59}$

Art. 70. O Conselho Nacional deverá apreciar, até dezembro 2008, a proposta de regras de desempenho elaborada pelo Departamento Nacional. ${ }^{60}$

\footnotetext{
${ }^{53}$ Vide Nota $^{\circ} 8$

${ }^{54}$ Vide Nota $^{\circ} 8$

${ }^{55}$ Vide $\operatorname{Nota}^{\circ} 8$

${ }^{56}$ Vide $\operatorname{Nota}^{\circ} 8$

${ }^{57}$ Vide Nota ${ }^{\circ} 8$

${ }^{58}$ Vide Nota $n^{0} 8$

${ }^{59}$ Vide Nota ${ }^{\circ} 8$

${ }^{60}$ Vide Nota ${ }^{\circ} 8$
} 